\title{
Targeted ablation of Fgf 23 demonstrates an essential physiological role of FGF23 in phosphate and vitamin D metabolism
}

\author{
Takashi Shimada, ${ }^{1}$ Makoto Kakitani, ${ }^{1}$ Yuji Yamazaki,${ }^{1}$ Hisashi Hasegawa,${ }^{1}$ \\ Yasuhiro Takeuchi, ${ }^{2}$ Toshiro Fujita, ${ }^{2}$ Seiji Fukumoto, ${ }^{3}$ Kazuma Tomizuka, ${ }^{1}$ \\ and Takeyoshi Yamashita ${ }^{1}$
}

\author{
${ }^{1}$ Pharmaceutical Research Laboratories, KIRIN Brewery Co., Takasaki, Gunma, Japan \\ ${ }^{2}$ Department of Medicine, University of Tokyo School of Medicine, Bunkyo-ku, Tokyo, Japan \\ ${ }^{3}$ Department of Laboratory Medicine, University of Tokyo Hospital, Bunkyo-ku, Tokyo, Japan
}

\begin{abstract}
Inorganic phosphate is essential for ECM mineralization and also as a constituent of important molecules in cellular metabolism. Investigations of several hypophosphatemic diseases indicated that a hormone-like molecule probably regulates serum phosphate concentration. FGF23 has recently been recognized as playing important pathophysiological roles in several hypophosphatemic diseases. We present here the evidence that FGF23 is a physiological regulator of serum phosphate and 1,25-dihydroxyvitamin D $\left(1,25[\mathrm{OH}]_{2} \mathrm{D}\right)$ by generating FGF23-null mice. Disruption of the Fgf23 gene did not result in embryonic lethality, although homozygous mice showed severe growth retardation with abnormal bone phenotype and markedly short life span. The $\mathrm{Fg} 2 \mathrm{2}^{-/-}$mice displayed significantly high serum phosphate with increased renal phosphate reabsorption. They also showed an elevation in serum $1,25(\mathrm{OH})_{2} \mathrm{D}$ that was due to the enhanced expression of renal 25 -hydroxyvitamin $\mathrm{D}-1 \alpha$-hydroxylase ( $1 \alpha$-OHase) from 10 days of age. These phenotypes could not be explained by currently known regulators of mineral homeostasis, indicating that FGF23 is essential for normal phosphate and vitamin D metabolism.
\end{abstract}

J. Clin. Invest. 113:561-568 (2004). doi:10.1172/JCI200419081.

\section{Introduction}

Serum calcium and phosphate concentrations are maintained in narrow ranges, indicating that they are regulated through hormonal mechanisms. This has been amply documented in the case of serum calcium concentration. Calcium-sensing receptors in the parathyroid glands sense changes in serum calcium and modulate the secretion of parathyroid hormone (PTH), the main calcium-regulating hormone (1). $\mathrm{PTH}$, in turn, regulates serum calcium by enhancing

Received for publication May 30, 2003, and accepted in revised form December 16, 2003.

Address correspondence to: Takeyoshi Yamashita, Pharmaceutical Research Laboratories, KIRIN Brewery Co., 3 Miyahara, Takasaki, Gunma 370-1295, Japan. Phone: 81-27-346-9789; Fax: 81-27-346-1672;

E-mail: tyamashita@kirin.co.jp.

Conflict of interest: Takashi Shimada, Makoto Kakitani, Yuji Yamazaki, Hisashi Hasegawa, Kazuma Tomizuka, and Takeyoshi Yamashita are employees of KIRIN Brewery Co.

Nonstandard abbreviations used: 1,25 -dihydroxyvitamin $\mathrm{D}$ $\left(1,25[\mathrm{OH}]_{2} \mathrm{D}\right) ; 25$-hydroxyvitamin $\mathrm{D}-1 \alpha$-hydroxylase (1 $\alpha$-OHase); parathyroid hormone (PTH); X-linked hypophosphatemic rickets/osteomalacia (XLH); tumor-induced osteomalacia (TIO); autosomal-dominant hypophosphatemic rickets/osteomalacia (ADHR); alkaline phosphatase (ALP); brush border membrane vesicles (BBMV); type IIa sodium-phosphate cotransporter (NaPi-2a); mineralized bone volume/tissue volume ratio (mBV/TV); bone volume/tissue volume ratio (BV/TV); 25-hydroxyvitamin D-24-hydroxylase (24-OHase); tubular maximum transport of phosphate/GFR (TmP/GFR). osteoclastic bone resorption through osteoblastic cells in bone, increasing renal tubular reabsorption of calcium in the kidney, and controlling 1,25-dihydroxyvitamin $\mathrm{D}\left(1,25[\mathrm{OH}]_{2} \mathrm{D}\right)$ production (2). In contrast, although both PTH and $1,25(\mathrm{OH})_{2} \mathrm{D}$ can affect serum phosphate, it has been unclear how serum phosphate is maintained, since PTH secretion is mainly regulated by serum calcium (1).

$\mathrm{X}$-linked hypophosphatemic rickets/osteomalacia (XLH), tumor-induced osteomalacia (TIO), and autosomal-dominant hypophosphatemic rickets/osteomalacia (ADHR) share common clinical features, including hypophosphatemia due to renal phosphate wasting and impaired mineralization of bone (3). Because serum calcium and PTH are usually normal in patients with these diseases, the presence of a phosphaturic humoral factor named phosphatonin has been postulated $(3,4)$. Recent investigations of ADHR and TIO implicated FGF23 in the causation of these diseases (5-9). Continuous exposure to recombinant FGF23 reproduced hypophosphatemic osteomalacia and inappropriately low serum $1,25(\mathrm{OH})_{2} \mathrm{D}(6,10)$. The mutant form of FGF23 that derives from the causative missense mutations of ADHR was shown to be resistant to proteolytic processing that converts the biologically functional fulllength polypeptide into inactive fragments $(7,8)$. Furthermore, the elevated circulatory FGF23 levels were demonstrated not only in patients with TIO but 
also in those with XLH $(11,12)$. These results indicate that excess activity of FGF23 causes hypophosphatemia and impaired mineralization of bone associated with phosphatonin. In addition, recent reports have revealed that circulatory FGF23 could be detected in sera of normal humans $(11,12)$, implying the action of FGF23 in maintaining normal mineral homeostasis in the endocrine system. To decipher the physiological function of FGF23, we generated and analyzed FGF23-deficient mice.

\section{Methods}

Establishment of the FGF23-null mice. The genomic DNA corresponding to $5.2 \mathrm{~kb}$ of the $5^{\prime}$-flanking region, a part of exon 1 , and the following $3^{\prime}$-intronic sequence in the Fgf23 gene were isolated from a C57BL/6 genomic bacterial artificial chromosome library. These DNA fragments were subcloned into $5^{\prime}$ and $3^{\prime}$ sites of a neomycin-resistance gene to construct the targeting vector (Figure 1a). This targeting vector was introduced into TT2 ES cells (13) by electroporation to replace the $0.2-\mathrm{kb}$ fragment of DNA of exon 1 . The transformed clones carrying a targeted allele were selected by Southern blot analysis and microinjected into the eight-cell embryo prepared from ICR mice. Male chimeric mice with a germline transmission of the targeted allele were mated with female C57BL/ 6 mice to generate heterozygous offspring. Homozygous founders were generated by mating these heterozygous mice. All mice were fed with a standard rodent chow containing $1.1 \% \mathrm{P}$ and $1.0 \% \mathrm{Ca}$ (CLEA Japan Inc., Tokyo, Japan) and tap water ad libitum. All studies using animals were reviewed and approved by the Institutional Animal Care and Use Committee at the Pharmaceutical Research Laboratories, KIRIN Brewery Co. (Takasaki, Japan).

Soft roentgenogram of femurs. The femurs were fixed in $4 \%$ paraformaldehyde and were exposed to X-rays at 0.1 $\mathrm{mA}$ and $25 \mathrm{kV}$ for 5 seconds using $\mu \mathrm{FX}-1000$ (Fujifilm Co., Tokyo, Japan). The image was developed by a BAS image analyzer (Fuji Photo Film Co.).

Bone histology. For double-labeling analysis, $30 \mathrm{mg} / \mathrm{kg}$ of tetracycline and then $30 \mathrm{mg} / \mathrm{kg}$ of calcein were injected intraperitoneally with a 3 -day interval between injections. The isolated femurs were fixed and stained with Villanueva bone stain. Tissues were then embedded in a methyl methacrylate resin (Wako Pure Chemical Industries Ltd., Osaka, Japan), and undecalcified sections with $4 \mu \mathrm{m}$ thickness were counterstained with Villanueva-Goldner counterstain. Histomorphometric analysis was carried out by choosing 24-26 fields in a femoral secondary cancellous bone.

Measurement of serum parameters. Blood samples were collected from the carotid artery (day 1 and 6) or heart (day 10 and thereafter) under anesthesia. Phosphate and calcium concentrations were determined using P-test WAKO and Ca-test WAKO, respectively (Wako Pure Chemical Industries Ltd.). Serum PTH and $1,25(\mathrm{OH})_{2} \mathrm{D}$ were determined by Rat Intact PTH RIA Kit (Immutopics, Inc., San Clemente, California, USA) and RIA Kit (TFB Co., Tokyo, Japan), respectively. Serum FGF23 was measured by a sandwich ELISA (12) established for a detection of full-length human FGF23. Immunoprecipitation followed by
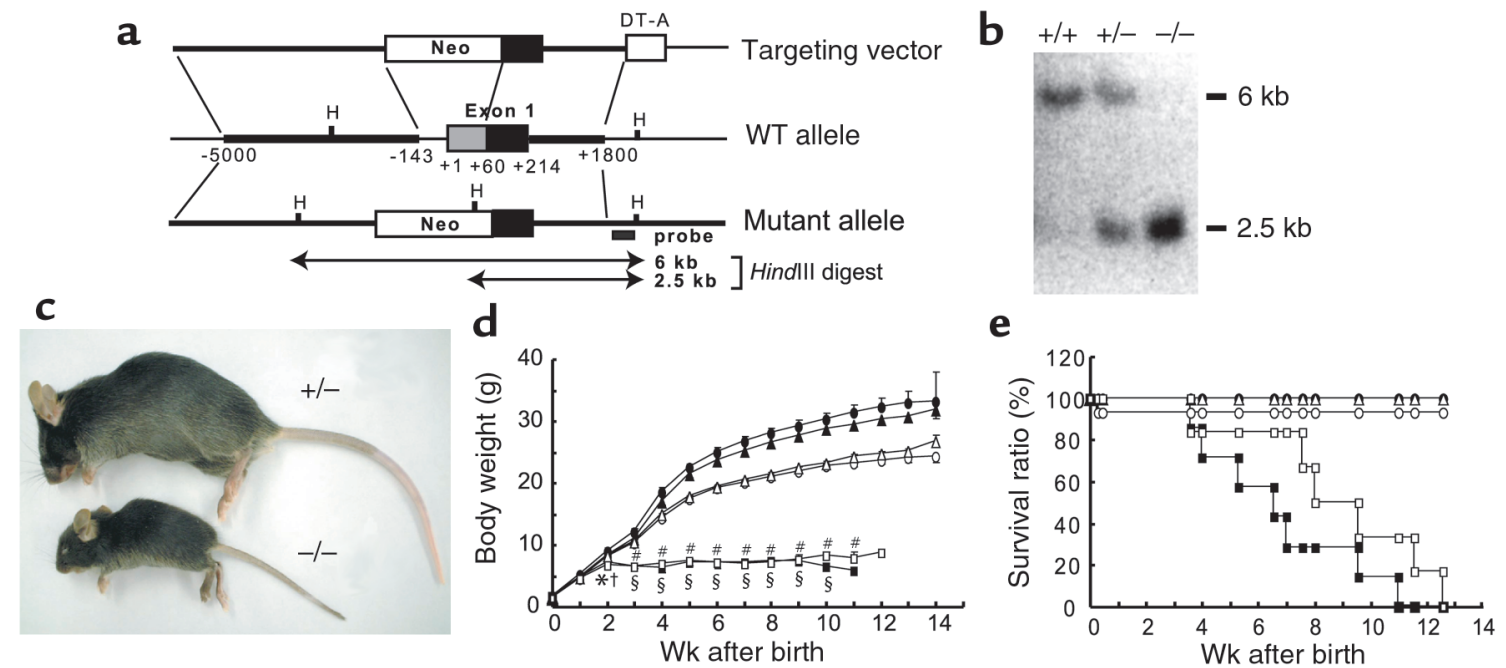

\section{Figure 1}

Establishment of FGF23-null mice. (a) Targeted ablation of Fgf23 gene. Construct of a targeting vector (top), wild-type allele (middle), and targeted mutant allele (bottom) are shown. DT-A, diphtheria toxin-A fragment; H, HindllI. (b) Genomic Southern blot analysis. Genomic DNAs $(5 \mu \mathrm{g})$ isolated from transfected ES clones were digested with HindIII and hybridized to the indicated probe. (c) Gross phenotypes of heterozygous and homozygous founders at 6 weeks of age. (d) Growth curves and (e) survival ratios for male (filled) or female (open) WT (circles), heterozygotes (triangles), and homozygotes (squares). Data are represented as mean \pm SEM. Statistical analysis in each sex was carried out by Dunnett's method. Statistically significant results are marked by asterisk (male) or cross (female) $\left({ }^{*} P<0.05, \S P<0.01,{ }^{\dagger} P<0.05,{ }^{\#} P<0.01\right)$. Numbers of animals used in this study: male WT $(+/+), n=9$; female WT, $n=15$; male heterozygotes $(+/-), n=20$; female heterozygotes, $n=19$; male homozygotes $(-/-), n=7$; female homozygotes, $n=6$. 
Western blotting demonstrated that the two mAbs used in this ELISA recognize mouse as well as human FGF23. In addition, a titration curve of serial dilutions of recombinant mouse FGF23 prepared by this ELISA was virtually identical to the standard curve produced using purified recombinant human FGF23 protein (data not shown), indicating that mouse FGF23 is quantitatively detectable by this ELISA. Results were expressed as values calculated from the standard curve using human FGF23. Urine samples were collected by rearing mice in metabolic cages (Sugiyamagen Co., Tokyo, Japan) for 24 hours. Serum alkaline phosphatase (ALP) activity, glucose, blood urea nitrogen (BUN), creatinine, total cholesterol, and triglycerides were determined by using the Hitachi 7180 autoanalyser (Hitachi High-Technologies Corp., Tokyo, Japan).
Measurement of sodium-dependent phosphate uptake activity of brush border membrane vesicles (BBMV). The BBMV were prepared by the method previously reported (14). The sodium-dependent phosphate uptake of the BBMV was measured by a rapid filtration method with several modifications (15).

Immunohistochemistry of type II a sodium-phosphate cotransporter (NaPi-2a) protein. The kidneys were fixed in 10\% paraformaldehyde, and embedded in paraffin. Sections of $3 \mu \mathrm{m}$ thickness were incubated with a polyclonal rabbit anti-mouse NaPi-2a antibody produced by immunizing rabbits with the C-terminal peptide of $\mathrm{NaPi}-2 \mathrm{a}$ (LALPAHHNATRL). The signals were detected by ENVISION+ HRP system (DakoCytomation, Kyoto, Japan).

Northern blotting. The DNA fragments used as probes for all experiments were prepared from the mouse kidney cDNA by PCR with the following

\section{Figure 2}

Histological analysis of bone. (a) Soft $X$-rays of femurs prepared from 7-weekold mice. (b and $\mathbf{c}$ ) Villanueva-Goldner stain of undecalcified femurs prepared from 2- and 7-week-old mice. (b) Distal metaphysis of femurs isolated at 2 weeks (upper) and 7 weeks (lower) of age. Original magnification, $\times 4$. (c) Growth plates of femurs at 2 weeks (upper) and 7 weeks (lower) of age. Mineralized bone tissues are colored in green, and unmineralized osteoid tissues are shown in orange. Original magnification, $\times 20$.

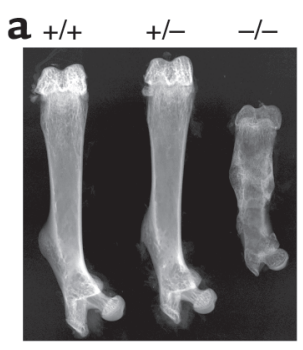

b

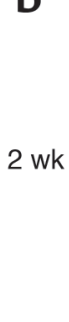

$+/+$
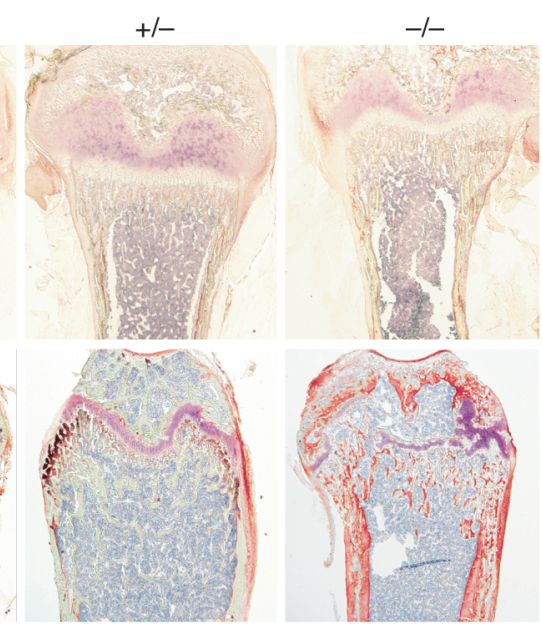

C
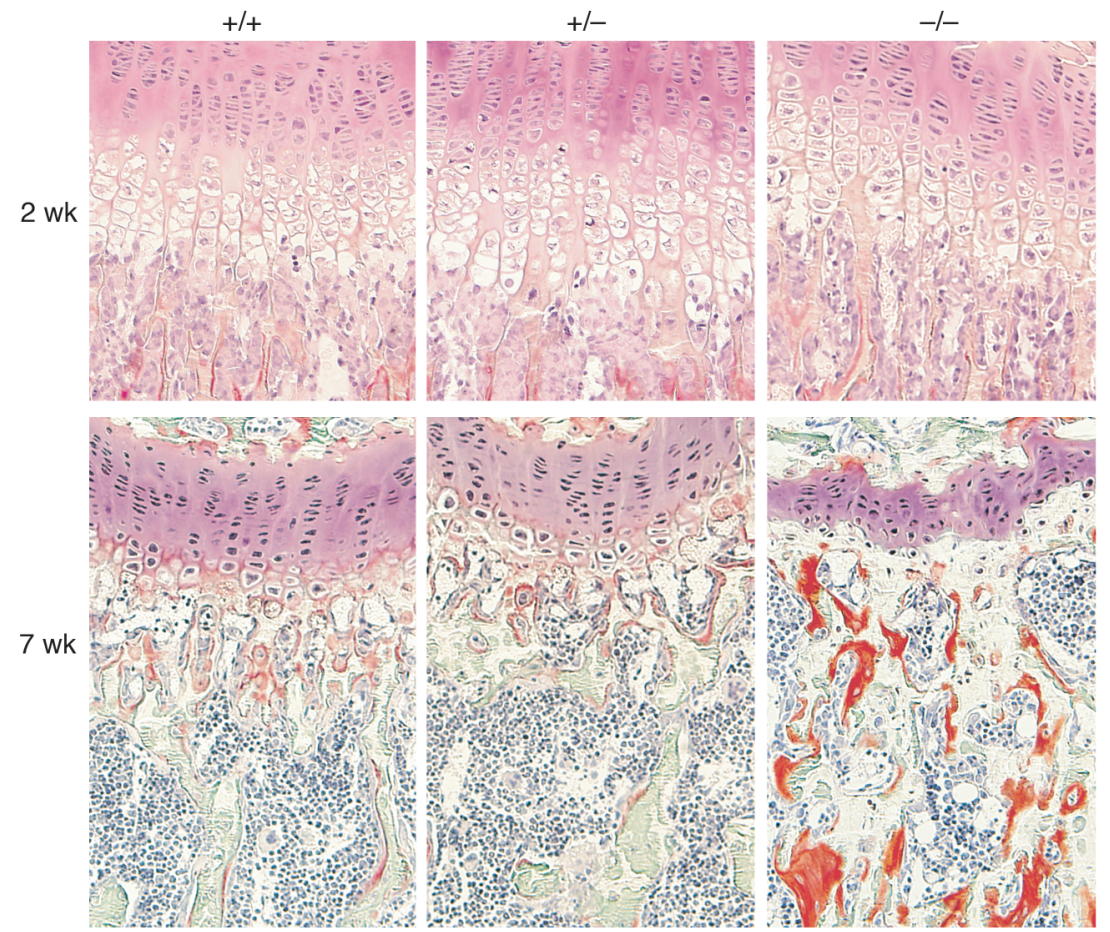
primer pairs. For 25 -hydroxyvitamin D-1 $\alpha$-hydroxylase ( $1 \alpha$-OHase): $5^{\prime}$-CAGACAGAGACATCCGTGTAG-3' and $5^{\prime}$-CCACATGGTCCAGGTTCAGTC- ${ }^{\prime}$; for 25hydroxyvitamin D-24-hydroxylase (24-OHase): $5^{\prime}$ CTCGGAACGTCACCTCCTTA- $3^{\prime}$ and $5^{\prime}$-CAGGCTGCTGGGAATATCTC- ${ }^{\prime}$; and for GAPDH: $5^{\prime}$-ACCACAGTCCATGCCATCAC- $3^{\prime}$ and $5^{\prime}$-TCCACCACCCTGTTGCTGTA$3^{\prime}$. Total RNA was isolated from the frozen kidneys using ISOGEN reagent (Nippon Gene Co., Tokyo, Japan). A $20-\mu \mathrm{g}$ sample of each of the RNA samples was electrophoresed and transferred to Hybond $\mathrm{N}^{+}$ (Amersham Biosciences Corp., Piscataway, New Jersey, USA). Radiolabeled probe was prepared using Megaprime labeling system (Amersham Biosciences Corp.). The membrane was hybridized with the ${ }^{32} \mathrm{P}$ labeled probe in PerfectHyb reagent (TOYOBO Co., Osaka, Japan) overnight at $65^{\circ} \mathrm{C}$. Then the blot was washed with a solution of $0.1 \times$ SSC and $0.5 \%$ SDS for 30 minutes at $65^{\circ} \mathrm{C}$. The signals were visualized by the BAS system (Fuji Photo Film Co.).

\section{Results}

Generation of the FGF23-null mice. Targeted ablation of the $\mathrm{Fg} f 23$ gene generated heterozygotes $\left(\mathrm{Fg} f \mathrm{C}^{+} /-\right)$and homozygotes $\left(\mathrm{Fg} f \mathrm{f3}^{-/-}\right)$(Figure 1, a and b). Mice with each genotype were born at the expected mendelian frequency. The heterozygotes did not show significant differences from WT mice in general appearance and growth (Figure 1, $\mathrm{c}$ and d). These phenotypes are consistent with the same serum level of FGF23 in heterozygotes $(120.1 \pm 4.4 \mathrm{pg} / \mathrm{ml}, n=3)$ at 9 weeks of age as that of age-matched WT mice $(126.0 \pm 2.8 \mathrm{pg} / \mathrm{ml}, n=13)$. Serum FGF23 could not be detected in homozygotes at this age, confirming a successful ablation of the Fgf23 gene $(n=7)$. However, marked growth retardation of homozygotes was observed by 13 days of age and thereafter, although at birth the body size and appearance of the Fof $23^{-1-}$ mice were not different from those of WT or heterozygous littermates (Figure 1d). Moreover, the life span of the Fgf $23^{-/-}$mice was markedly shorter than that of either WT mice or heterozygotes (Figure 1e). The ablation of FGF23 did not affect the developmental process of any organs by birth. However, the $\mathrm{KO}$ mice began to die at various ages after weaning, and no homozygotes survived more than 13 weeks. The survival ratios between male and female homozygous mice were not statistically different $(P=0.1455, \log$ rank test). An autopsy of a 12-week-old homozygous mouse demonstrated sparse skeletal muscle and fat tissues. Furthermore, atrophy of glomeruli and marked vascular calcification in the kidneys, accompanied by elevated serum BUN $(88.0 \mathrm{mg} / \mathrm{dl}$, obtained at 2 days before death) were observed. Therefore, the impaired renal function, as one possible reason for the short life span of the $\mathrm{Fg} 23^{-/-}$mice, was probably due to the constantly higher serum levels of both calcium and phosphate almost throughout the life span, as discussed later. In addition, that the $\mathrm{KO}$ mice were hypoglycemic for unknown reasons (as discussed later) may also have contributed to the short life span.
The FGF23-null mice exhibited an obvious immaturity of the reproductive organs that resulted in infertility. Severe and rapid atrophy of the thymus and reduction of the spleen cells were observed after weaning, although these organs appeared to be normal at 3 weeks of age (data not shown). The Fgf23-/- mice also demonstrated marked decrease in peripheral lymphocytes (heterozygotes, 5,455 $\pm 1,424$ cells $/ \mu \mathrm{l}, n=4$; homozygotes, $833 \pm 140$ cells $/ \mu \mathrm{l}, n=4, P<0.05$ ).

Abnormal bone of $\mathrm{Fgf2} 23^{-/}$mice. The $\mathrm{Fg} 23^{-/-}$mice showed abnormal bone development. As shown in Figure 2a, the femurs isolated from 7-week-old Fgf $23^{-/-}$mice were very short, and the soft X-ray images of cortical bone demonstrated a marked reduction in mineral content. However, bone diameter was disproportionately wide and the epiphysis relatively large. Histological analysis revealed that the femurs isolated from 2-week-old homozygous mice appeared to be normal when the growth retardation became obvious (Figure 2, b and c). In contrast, in 7week-old $\mathrm{Fg} 2 \mathrm{f3}^{-\mathrm{-}}$ mice, the growth plate was severely disorganized and hypertrophic chondrocytes were not observed. In addition, a marked accumulation of unmineralized osteoids was seen in cortical bone and secondary spongiosa (Figure 2, b and c). Similar accumulation of osteoid was seen in tibia and calvarial bone (data not shown). Table 1 summarizes the results of bone histomorphometry in femoral secondary cancellous bones at 7 weeks of age. The mineralized bone volume/tissue volume ratio (mBV/TV) significantly decreased in the $\mathrm{KO}$ mice, although the

\section{Table 1}

Results of bone histomorphometry in 7-week-old mice

$\begin{array}{lccc} & F g f 23^{+/+} & F g f 23^{+/-} & F g f 23^{-/-} \\ \text {Tissue area }\left(\mathrm{mm}^{2}\right) & 2.1 \pm 0.1 & 2.1 \pm 0.1 & 1.4 \pm 0.1^{\mathrm{A}} \\ \text { BV/TV }(\%) & 7.4 \pm 0.9 & 7.3 \pm 1.8 & 4.0 \pm 1.6 \\ \mathrm{mBV} / \mathrm{TV}(\%) & 7.2 \pm 0.8 & 7.1 \pm 1.7 & 1.9 \pm 1.0^{\mathrm{A}} \\ \text { Tb.Th }(\mathrm{mm}) & 25.3 \pm 1.5 & 23.4 \pm 2.0 & 33.6 \pm 3.1^{\mathrm{A}} \\ \text { Tb.N }(/ \mathrm{mm}) & 2.9 \pm 0.2 & 2.9 \pm 0.4 & 1.1 \pm 0.3^{\mathrm{A}} \\ \text { Tb.Sp (mm) } & 339 \pm 34 & 378 \pm 53 & 1368 \pm 321^{\mathrm{A}} \\ \text { OV/BV (\%) } & 2.8 \pm 0.3 & 2.3 \pm 0.3 & 58.3 \pm 7.2^{\mathrm{A}} \\ \text { OV/BS (\%) } & 14.3 \pm 1.1 & 13.3 \pm 0.8 & 71.5 \pm 4.2^{\mathrm{A}} \\ \text { O.Th (mm) } & 2.5 \pm 0.1 & 1.9 \pm 0.1 & 13.2 \pm 1.2^{\mathrm{A}} \\ \text { Ob.S/BS (\%) } & 25.8 \pm 1.1 & 24.2 \pm 1.9 & 2.2 \pm 0.8^{\mathrm{A}} \\ \text { ES/BS (\%) } & 4.0 \pm 0.4 & 4.2 \pm 0.7 & 1.1 \pm 0.5^{\mathrm{A}} \\ \text { Oc.N/B.Pm }(/ 100 \mathrm{~mm}) & 169 \pm 10 & 142 \pm 29 & 25 \pm 13^{\mathrm{A}} \\ \text { Oc.S/BS (\%) } & 2.1 \pm 0.2 & 2.0 \pm 0.4 & 0.3 \pm 0.2^{\mathrm{A}} \\ \text { MAR (/day) } & 1.8 \pm 0.1 & 1.9 \pm 0.1 & \mathrm{ND} \\ \text { MS/BS (\%) } & 7.8 \pm 1.2 & 5.1 \pm 0.6 & \mathrm{ND} \\ \text { BFR/BS } & 5.1 \pm 0.8 & 3.6 \pm 0.6 & \mathrm{ND}\end{array}$

Hetero, heterozygote; Homo, homozygote; BV/TV, bone volume/tissue volume; $\mathrm{mBV} / \mathrm{TV}$, mineralized bone volume/tissue volume; Tb.Th, trabecular thickness; Tb.N, trabecular number; Tb.Sp, trabecular separation; OV/BV, osteoid volume/bone volume; OV/BS, osteoid volume/bone surface; O.Th, osteoid thickness; Ob.S/BS, osteoblast surface/bone surface; ES/BS, eroded surface/bone surface; Oc.N/B.Pm, osteoclast number/bone perimeter; Oc.S/BS, osteoclast surface/bone surface; MAR, mineral apposition rate; MS/BS, mineralizing surface/bone surface; BFR/BS, bone formation rate/bone surface. The data represent mean \pm SEM. WT, $n=8$; heterozygotes, $n=8$; homozygotes, $n=7$. ${ }^{A} P<0.01$, evaluated by Dunnett's method. ND, not determined. 

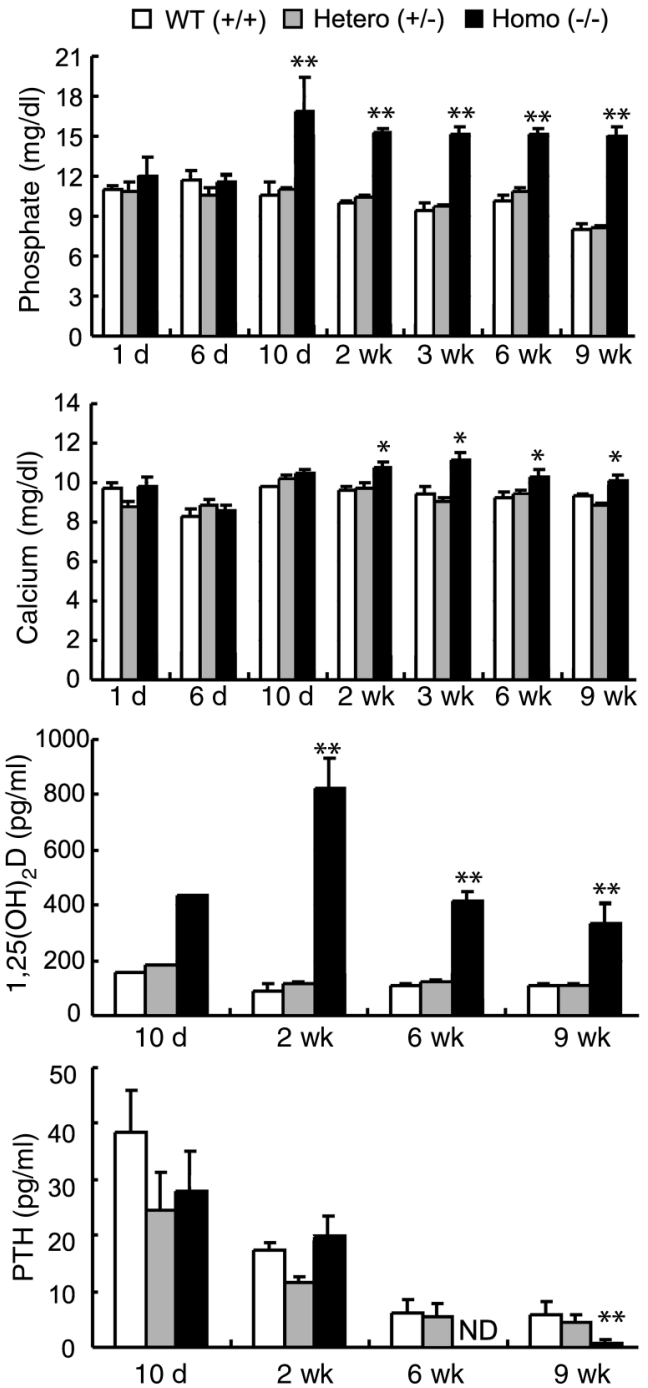

Figure 3

Comparison of serum parameters. Blood samples were collected from carotid artery (day 1 and 6) or heart (day 10 and thereafter) under conditions of anesthesia. Because sufficient amounts of blood could not be obtained from mice aged younger than 10 days, sera were pooled in each genotype for measurement of $1,25(\mathrm{OH})_{2} \mathrm{D}$. Other results represent mean \pm SEM. The numbers of mice killed at each age were variable (average; WT $n=5$, heterozygotes $n=9$, and homozygotes $n=6)$. Statistical analysis was carried out by Dunnett's method for comparison of multiple means $\left({ }^{*} P<0.05\right.$; $\left.{ }^{*} P<0.01\right)$. ND, not detected.

bone volume/tissue volume ratio (BV/TV) was not statistically changed. There were fewer trabeculae present than in normal littermates, while the trabecular thickness was relatively greater as a result of osteoid accumulation. The osteoid volume, thickness, and surface area were markedly increased in the Fgf23-1- mice. Both osteoblast and osteoclast surface areas were markedly reduced in the null mice, indicating that bone turnover was suppressed. The double-labeling analysis failed to determine the parameters for mineralization because of an absence of the labeled mineralization surface in the null mice. None of the parameters that we examined were statistically different between WT and heterozygous mice.

Serum parameters in the Fgf $23^{-/-}$mice. We had previously reported that administration of FGF23 reproduced the typical features of TIO including hypophosphatemia and low serum $1,25(\mathrm{OH})_{2} \mathrm{D}(6)$. In contrast, the $\mathrm{Fg} 23^{-/-}$mice showed significant elevations of serum phosphate, calcium, and $1,25(\mathrm{OH})_{2} \mathrm{D}$ (Figure 3). Serum phosphate concentrations were significantly elevated from day 10 after birth, and those elevations were maintained at least up to 9 weeks of age. Serum $1,25(\mathrm{OH})_{2} \mathrm{D}$ of the $\mathrm{KO}$ mice also began to increase at day 10. At this point, serum FGF23 was detected in WT and in heterozygous mice (WT, $186.4 \pm 14.1 \mathrm{pg} / \mathrm{ml}, n=10$; heterozygotes; $205.5 \pm 21.3 \mathrm{pg} / \mathrm{ml}, n=9$ ) but not in $\mathrm{KO}$ mice $(n=5)$. Although FGF23 protein $(10-61 \mathrm{pg} / \mathrm{ml})$ was detected in breast milk collected from the female heterozygous mice nursing homozygous pups, it was not sufficient to compensate for the lack of serum FGF23 to rescue the phenotypes in the $F g f 23^{-/-}$mice. Elevation of serum calcium observed from 2 weeks after birth was modest but significant. Serum PTH of the FGF23-null mice were significantly decreased at 6 or 9 weeks of age, but not at 10 days or 2 weeks. This decrease in PTH may be at least in part due to the increased serum calcium and $1,25(\mathrm{OH})_{2} \mathrm{D}$. The FGF23null mice exhibited significant increases in serum ALP activities. The marked elevation was already observed at 2 weeks and was maintained at 6 weeks (Table 2). Hypoglycemia was observed from 2 weeks of age and became remarkable at 3 weeks and afterward (Table 2). In addition, serum total cholesterol was increased and triglycerides were decreased (Table 2). Heterozygotes did not show any changes in serum parameters examined in comparison with those of WT mice.

Altered expressions of key molecules for mineral homeostasis. Serum $1,25(\mathrm{OH})_{2} \mathrm{D}$ is mainly determined by activities of the renal enzymes $1 \alpha$-OHase, which increases the serum concentrations of $1,25(\mathrm{OH})_{2} \mathrm{D}$, and 24-OHase, which metabolizes and decreases serum $1,25(\mathrm{OH})_{2} \mathrm{D}$ (16). To seek an explanation for the high serum $1,25(\mathrm{OH})_{2} \mathrm{D}$ in the FGF23-null mice, we examined the expression of these enzymes by Northern blot. The expression of $1 \alpha-O H a s e$ was increased in the $\mathrm{Fg} f 3^{-/-}$ mice from at least day 10 , when the serum $1,25(\mathrm{OH})_{2} \mathrm{D}$ also started to rise, and the increased $1 \alpha$-OHase mRNA was maintained thereafter (Figure 4a). In addition, the enhanced mRNA level of 24-OHase was also observed at 3 weeks and thereafter in the $\mathrm{Fg} f 23^{-/-}$mice (Figure 4a). Since the increase of 24-OHase mRNA occurred at 3 weeks, when serum $1,25(\mathrm{OH})_{2} \mathrm{D}$ levels had already increased, it is probable that this enhanced 24-OHase expression was promoted by the increased $1,25(\mathrm{OH})_{2} \mathrm{D}$ levels in the $\mathrm{Fg} \mathrm{f}^{23^{-/-}}$mice. Thus, upregulated $1 \alpha$-OHase expression seems to be the main reason for the significant elevation of serum $1,25(\mathrm{OH})_{2} \mathrm{D}$ in the $\mathrm{KO}$ mice.

Serum phosphate level is mainly maintained by renal phosphate reabsorption, which is regulated by the amount of NaPi-2a in brush border membrane of the 
Table 2

Serum parameters for experimental mice at 6 weeks of age

\begin{tabular}{lccr}
\hline & Fgf23 & & \\
& $640 \pm 74$ & $590 \pm 22$ & $2103 \pm 262^{+/+}$ \\
ALP activity (IU/liter) & $237.6 \pm 12.3$ & $224.6 \pm 5.9$ & $96.6 \pm 6.1^{\mathrm{A}}$ \\
Glucose $(\mathrm{mg} / \mathrm{dl})$ & $73.5 \pm 1.5$ & $77.2 \pm 2.7$ & $109.4 \pm 5.1^{\mathrm{A}}$ \\
Total cholesterol (mg/dl) & Fgf23-/- \\
Triglycerides $(\mathrm{mg} / \mathrm{dl})$ & $128.1 \pm 14.1$ & $125.0 \pm 12.9$ & $15.5 \pm 5.7^{\mathrm{A}}$
\end{tabular}

The results represent mean $\pm \mathrm{SEM}$. The numbers of mice used in this study were as follow: WT, $n=6$; heterozygotes, $n=18$; homozygotes, $n=6$. ${ }^{A} P<0.01$, evaluated by Dunnett's method.

renal proximal tubular cells (17). Actually, 6-week-old FGF23-KO mice demonstrated the increased tubular maximum transport of phosphate/GFR (TmP/GFR), suggesting that hyperphosphatemia in the $\mathrm{Fg} f 23^{-/-}$ mice was due to the increased renal phosphate reabsorption (Figure $4 \mathrm{~b}$ ). Therefore, we analyzed the expression of $\mathrm{NaPi}-2 \mathrm{a}$ to clarify the mechanism of this enhanced renal phosphate reabsorption. Figure $4 c$ shows the results of immunohistochemical analysis for NaPi-2a with kidney sections prepared from 6-weekold mice. Despite remarkable hyperphosphatemia, $\mathrm{NaPi}-2 \mathrm{a}$ protein in the $\mathrm{KO}$ mice was more localized to the apical surface of proximal tubules, confirming there was the enhanced phosphate reabsorption in those mice. This finding was further confirmed by a significant increase in sodium-dependent phosphateuptake activity of kidney BBMV in the KO mice (heterozygotes, $396.4 \pm 88.2 \mathrm{pmol} / \mathrm{mg} / \mathrm{min}, n=5$; homozygotes, $632.6 \pm 105.8 \mathrm{pmol} / \mathrm{mg} / \mathrm{min}, n=6, P<0.05$, at 9 weeks). PTH is known to induce renal phosphate excretion by rapidly decreasing $\mathrm{NaPi}-2 \mathrm{a}$ on the apical surface of proximal tubules (18). Therefore, it is possi- ble that the decreased PTH level in the Fgf $23^{-/-}$mice at 6-9 weeks might have contributed to the disordered response of NaPi-2a. However, decreased PTH levels were not observed at 10 days and 2 weeks, when hyperphosphatemia was already present, indicating that suppression of PTH is not required for hyperphosphatemia in the FGF23-null mice. Thus, enhanced renal phosphate reabsorption via NaPi-2a is likely to be one of the major reasons for severe hyperphosphatemia in the FGF23-null mice.

\section{Discussion}

The mutant mice lacking FGF23 exhibited severe hyperphosphatemia, with enhanced renal phosphate reabsorption and high serum $1,25(\mathrm{OH})_{2} \mathrm{D}$. In addition, these phenotypes are the mirror images of those in previously reported animal studies in which administration of FGF23 caused hypophosphatemia and low serum $1,25(\mathrm{OH})_{2} \mathrm{D}(6,7,10)$. In contrast, heterozygotes showed no abnormality in any of the parameters examined, including serum FGF23. These results clearly indicate that production and serum concentrations of FGF23 are tightly regulated and that this regulatory mechanism can compensate for the absence of one allele of the Fgf 23 gene, although the precise source and mechanism of regulation of FGF23 production are not sufficiently clear. Therefore, it is suggested that FGF23 is acting physiologically to reduce serum phosphate and $1,25(\mathrm{OH})_{2} \mathrm{D}$ levels.

Renal production of $1,25(\mathrm{OH})_{2} \mathrm{D}$ is stimulated by PTH and hypophosphatemia, and inhibited by $1,25(\mathrm{OH})_{2} \mathrm{D}$ and hypercalcemia $(16,19,20)$. The $\mathrm{Fg} 23^{-/-}$mice showed hyperphosphatemia, hypercalcemia, high serum $1,25(\mathrm{OH})_{2} \mathrm{D}$, and suppressed PTH, all of which have been described to suppress
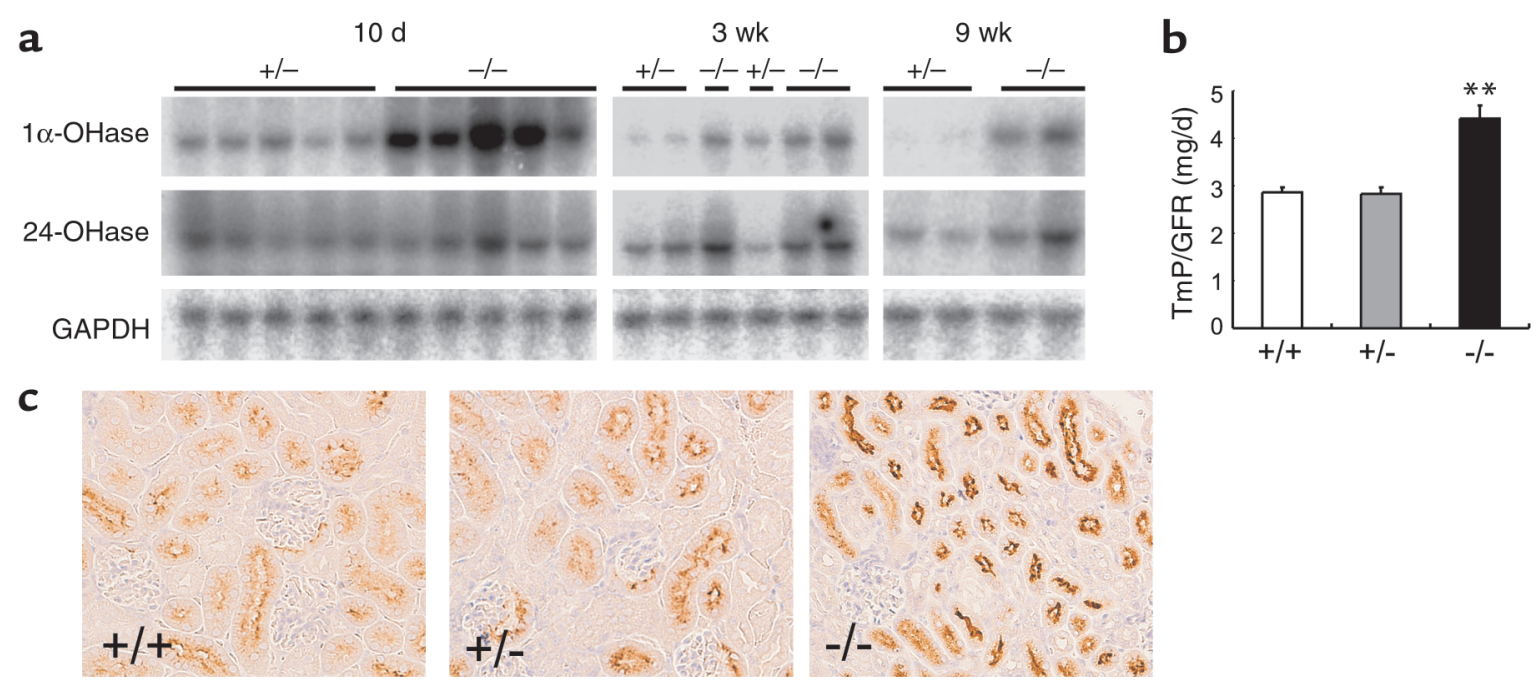

Figure 4

Key molecules for serum phosphate and $1,25(\mathrm{OH})_{2} \mathrm{D}$ levels. (a) Northern blot analysis of renal $1 \alpha-\mathrm{OH}$ ase and 24-OHase mRNAs. The blots were reprobed with a GAPDH fragment to confirm integrity of the electrophoresed RNAs. (b) TmP/GFR. Mice ( 6 weeks old) were reared in metabolic cages to collect urine samples for 24 hours. The results represent mean \pm SEM. WT, $n=6$; heterozygotes, $n=6$; homozygotes, $n=6$. ${ }^{*} P<0.01$, evaluated by Dunnett's method. (c) Immunohistochemistry of renal NaPi-2a protein at 6 weeks of age. 
$1,25(\mathrm{OH})_{2} \mathrm{D}$ production. However, the $\mathrm{KO}$ mice showed sustained elevation of $1 \alpha$-OHase expression and high $1,25(\mathrm{OH})_{2} \mathrm{D}$ levels at least from 10 days of age. On the contrary, our preliminary experiment demonstrated that injecting recombinant FGF23 into the $\mathrm{Fg} 2 \mathrm{3}^{-/-}$mice resulted in a significant reduction in serum $1,25(\mathrm{OH})_{2} \mathrm{D}$ within 8 hours (untreated WT mice, $152.1 \pm 17.9 \mathrm{pg} / \mathrm{ml}$; untreated homozygotes, $707.6 \pm 258.2 \mathrm{pg} / \mathrm{ml}$; FGF23-treated homozygotes, $79.9 \pm 9.0 \mathrm{pg} / \mathrm{ml}$ ). Therefore, it is likely that FGF23 is physiologically suppressing the renal $1 \alpha$-OHase expression cooperating or competing with several humoral factors such as PTH and $1,25(\mathrm{OH})_{2} \mathrm{D}$ itself. Although we were unable to evaluate the serum $1,25(\mathrm{OH})_{2} \mathrm{D}$ in homozygotes at 6 days of age because there were insufficient sera available for the measurement, we could detect circulatory FGF23 in 6-day-old WT mice $(154.2 \pm 22.3 \mathrm{pg} / \mathrm{ml}, n=4)$. Because hyperphosphatemia of the $\mathrm{KO}$ mice first appeared at 10 days after birth and other phenotypes at later times, FGF23 seems to be less important in newborn mice and the FGF23-independent phosphate-handling mechanism is probably dominant at this stage.

One possibility is that the regulatory mechanism of intestinal and renal phosphate handling is immature and rather insensitive to hormone-dependent changes of phosphate influx and efflux. The other possibility is that another phosphate-regulatory factor present in milk plays a dominant role in regulating serum phosphate.

Because excess actions of FGF23 result in rickets/ osteomalacia, it was surprising that the Fgf23 $3^{-/-}$mice also exhibited the disorganized growth plate and accumulation of osteoid in cortical and calvarial bones. Although the precise mechanism of this abnormal bone development is not clear at the moment, the elevated serum $1,25(\mathrm{OH})_{2} \mathrm{D}$ may have contributed to these changes. The increase of osteoid has been reported in the 24-OHase-deficient mice that demonstrated marked elevation of $1,25(\mathrm{OH})_{2} \mathrm{D}(21)$. The other possible reason for the abnormal bone development may be a decreased PTH level. PTH is a potent anabolic factor for bone formation, and its absence is known to suppress bone turnover (22). The significant reductions in both osteoblast and osteoclast surface areas in the $\mathrm{KO}$ mice may be caused by the deficient PTH action. However, increased osteoid cannot be explained by suppressed turnover of bone. In contrast, it is possible that FGF23 has a direct action on bone metabolism. Actually, a recent report showed expression of FGF23 in bone, suggesting an unknown function of FGF23 in bone metabolism (23). Additional studies, such as an investigation of the receptor and the signaling pathway, will be necessary to clarify these issues.

It has been reported that administration of $1,25(\mathrm{OH})_{2} \mathrm{D}_{3}$ induces a positive balance of phosphate and calcium (16). A recent report has shown that expression of intestinal type IIb sodium-dependent phosphate cotransporter, which is thought to be involved in active phosphate transport in the intestine, can be regulated by $1,25(\mathrm{OH})_{2} \mathrm{D}(24)$. Thus, increased serum $1,25(\mathrm{OH})_{2} \mathrm{D}$ may have contributed to hyperphosphatemia in the $\mathrm{Fg} 2 \mathrm{3}^{-/-}$mice, at least in part. In addition, the FGF23-null mice demonstrated enhanced renal phosphate-uptake activities and more restricted distribution of $\mathrm{NaPi}-2 \mathrm{a}$ on the apical side of the proximal tubule, which should be downregulated in the presence of hyperphosphatemia in normal animals (25). Bai et al. have reported that continuous administration of FGF23 induced the downregulation of NaPi-2a (10), and we have also observed the decreased NaPi-2a expression at 8-13 hours after a single injection of FGF23 into WT mice (26). Furthermore, 2-week-old Fgf23-/- mutant mice showed normal BUN levels compared with those of control littermates (WT, $18.6 \pm 1.6 \mathrm{mg} / \mathrm{dl}, n=3$; heterozygotes, $19.9 \pm 1.3$ $\mathrm{mg} / \mathrm{dl}, n=3$; homozygotes, $22.6 \pm 2.2 \mathrm{mg} / \mathrm{dl}, n=4)$, while homozygous mice by that age had already demonstrated significant hyperphosphatemia (Figure 3). Therefore, these results indicate that physiological response to hyperphosphatemia is abolished in the Fgf $23^{-/-}$mice and demonstrate the essential role of FGF23 in the regulation of renal phosphate reabsorption. Although the extremely small body size of Fgf23-/mice did not allow us to analyze the effect of parathyroidectomy on serum phosphate, our previous study demonstrated that FGF23 is able to reduce serum phosphate levels in parathyroidectomized animals (26). In addition, hyperphosphatemia of the $\mathrm{KO}$ mice observed at 10 days and 2 weeks after birth was associated with normal serum PTH levels. These results indicate that hyperphosphatemia of the $\mathrm{KO}$ mice is induced by a PTH-independent mechanism.

In contrast, it remains unclear whether FGF23 plays important roles in other physiological events besides mineral homeostasis. When we fed the $\mathrm{Fg} f \mathrm{3}^{-/-}$mice with a low-phosphate $\operatorname{diet}\left(\mathrm{P}_{\mathrm{i}} 0.2 \%\right.$, Ca $\left.0.5 \%\right)$ from just after weaning ( 4 weeks, $n=6$ ), $50 \%$ of homozygous mice survived more than 13 weeks. However, these mice with prolonged life span still demonstrated severe growth retardation (7.4-12.4 g body weight), hypoglycemia, and elevated $1,25(\mathrm{OH})_{2} \mathrm{D}(670.1 \pm 108.8 \mathrm{pg} / \mathrm{ml})$, although serum phosphate was successfully decreased $(5.8 \pm 2.3 \mathrm{mg} / \mathrm{dl})$. Thus, hyperphosphatemia itself is not sufficient to result in these phenotypes of the null mice. Atrophy of thymus and spleen became apparent only after weaning in FGF23-null mice. These results suggest that metabolic changes such as hyperphosphatemia and high serum $1,25(\mathrm{OH})_{2} \mathrm{D}$, rather than the deficiency of FGF23 itself, are responsible for abnormalities in lymphocytes. Actually, $1,25(\mathrm{OH})_{2} \mathrm{D}$ has been reported to be a potent regulator of the immune system. Additional studies are necessary to clarify the abnormalities in these tissues of FGF23-null mice.

In summary, here we have clarified the essential roles of FGF23 in the physiological regulation of phosphate and vitamin $\mathrm{D}$ metabolism. These findings provide new insights for the understanding of bone and mineral metabolism. Additional studies using these $\mathrm{Fg} 2 \mathrm{3}^{-/}$ 
mice, together with exploration of the receptor for FGF23 and of the tissues responsible for FGF23 production should more precisely decipher the physiological significance of FGF23.

\section{Acknowledgments}

This work was supported in part by grants from the Ministry of Education, Culture, Sports, Science and Technology, and from the Ministry of Health, Labour and Welfare, Japan. We gratefully thank C. Ando, A. Ohguma, and R. Hino for their excellent technical assistance, and $\mathrm{K}$. Iijima and R. Imai for helpful discussions and assistance.

1. Brown, E.M., et al. 1993. Cloning and characterization of an extracellular $\mathrm{Ca}(2+)$-sensing receptor from bovine parathyroid. Nature. 366:575-580.

2. Fitzpatrick, L.A., and Bilezikian, J.P. 1996. Actions of parathyroid hormone. In Principles of bone biology. J.P. Bilezikian, L.G. Raisz, and G.A. Rodan, editors. Academic Press Inc. San Diego, California, USA. 339-346.

3. Drezner, M.K. 2000. PHEX gene and hypophosphatemia. Kidney Int 57:9-18.

4. Econs, M.J., and Drezner, M.K. 1994. Tumor-induced osteomalaciaunveiling a new hormone. N. Engl. J. Med. 330:1679-1681.

5. The ADHR Consortium. 2000. Autosomal dominant hypophosphataemic rickets is associated with mutations in FGF23. Nat. Genet. 26:345-348.

6. Shimada, T., et al. 2001. Cloning and characterization of FGF23 as a causative factor of tumor-induced osteomalacia. Proc. Natl. Acad. Sci. U. S. A. 98:6500-6505.

7. Shimada, T., et al. 2002. Mutant FGF-23 responsible for autosomal dominant hypophosphatemic rickets is resistant to proteolytic cleavage and causes hypophosphatemia in vivo. Endocrinology. 143:3179-3182.

8. White, K.E., et al. 2001. Autosomal-dominant hypophosphatemic rickets (ADHR) mutations stabilize FGF-23. Kidney Int. 60:2079-2086.

9. White, K.E., et al. 2001. The autosomal dominant hypophosphatemic rickets (ADHR) gene is a secreted polypeptide overexpressed by tumors that cause phosphate wasting. J. Clin. Endocrinol. Metab. 86:497-500.

10. Bai, X.Y., Miao, D., Goltzman, D., and Karaplis, A.C. 2003. The autosomal dominant hypophosphatemic rickets R176Q mutation in FGF23 resists proteolytic cleavage and enhances in vivo biological potency. J. Biol. Chem. 278:9843-9849.
11. Jonsson, K.B., et al. 2003. Fibroblast growth factor 23 in oncogenic osteomalacia and X-linked hypophosphatemia. N. Engl. J. Med. 348:1656-1663.

12. Yamazaki, Y., et al. 2002. Increased circulatory level of biologically active full-length FGF-23 in patients with hypophosphatemic rickets/osteomalacia. J. Clin. Endocrinol. Metab. 87:4957-4960.

13. Yagi, T., et al. 1993. A novel negative selection for homologous recombinants using diphtheria toxin A fragment gene. Anal. Biochem. 214:77-86.

14. Hopfer, U., Nelson, K., Perrotto, J., and Isselbacher, K.J. 1973. Glucose transport in isolated brush border membrane from rat small intestine. J. Biol. Chem. 248:25-32.

15. Kessler, M., et al. 1978. A modified procedure for the rapid preparation of efficiently transporting vesicles from small intestinal brush borde membranes. Their use in investigating some properties of D-glucose and choline transport systems. Biochim. Biophys. Acta. 506:136-154.

16. Brown, A.J., Dusso, A., and Slatopolsky, E. 1999. Vitamin D. Am. J. Physiol. 277:F157-F175.

17. Beck, L., et al. 1998. Targeted inactivation of Npt2 in mice leads to severe renal phosphate wasting, hypercalciuria, and skeletal abnormalities. Proc. Natl. Acad. Sci. U. S. A. 95:5372-5377.

18. Murer, H., et al. 1996. Renal brush border membrane Na/Pi-cotransport molecular aspects in PTH-dependent and dietary regulation. Kidney Int. 49:1769-1773.

19. Brenza, H.L., and DeLuca, H.F. 2000. Regulation of 25-hydroxyvitamin $\mathrm{D}_{3}-1 \alpha$-hydroxylase gene expression by parathyroid hormone and 1,25-dihydroxyvitamin $\mathrm{D}_{3}$. Arch. Biochem. Biophys. 381:143-152.

20. Takeyama, K., et al. 1997. 25-Hydroxyvitamin $\mathrm{D}_{3} 1 \alpha$-hydroxylase and vitamin D synthesis. Science. 277:1827-1830.

21. St-Arnaud, R., et al. 2000. Deficient mineralization of intramembranous bone in vitamin D-24-hydroxylase-ablated mice is due to elevated 1,25-dihydroxyvitamin D and not to the absence of 24,25-dihydroxyvitamin D. Endocrinology. 141:2658-2666.

22. Langdahl, B.L., Mortensen, L., Vesterby, A., Eriksen, E.F., and Charles, P. 1996. Bone histomorphometry in hypoparathyroid patients treated with vitamin D. Bone. 18:103-108.

23. Riminucci, M., et al. 2003. FGF-23 in fibrous dysplasia of bone and its relationship to renal phosphate wasting. J. Clin. Invest. 112:683-692. doi:10.1172/JCI200318399.

24. Hattenhauer, O., Traebert, M., Murer, H., and Biber, J. 1999. Regulation of small intestinal Na-P(i) type IIb cotransporter by dietary phosphate intake. Am. J. Physiol. 277:G756-G762.

25. Murer, H., and Biber, J. 1997. A molecular view of proximal tubular inorganic phosphate $\left(\mathrm{P}_{\mathrm{i}}\right)$ reabsorption and of its regulation. Pflugers Arch. 433:379-389.

26. Shimada, T., et al. 2004. FGF-23 is a potent regulator of the vitamin D metabolism and phosphate homeostasis. J. Bone Miner. Res. In press. 